\title{
The Influence of Multiple Representation in Physics Learning to Students in Understanding Physics Material and Scientific Consistency
}

\author{
S. Nulhaq \\ Physics Education Study Program \\ SPs-Universitas Pendidikan Indonesia \\ Bandung, Indonesia \\ sidiknulhaq@gmail.com
}

\author{
A. Setiawan \\ Faculty of Technology and Vocational Education \\ Universitas Pendidikan Indonesia \\ Bandung, Indonesia
}

\begin{abstract}
This research was to obtain an overview the ratio of ability to increase understanding and scientific consistency between students who get Physics learning using multiple representations and students who get Physics learning without using multiple representations. Physics learning using multiple representations require students to interpret a concept in some representations so that can improve the ability of students in understanding of Physics material and scientific consistency. This research is using a quasi-experimental method with Nonequivalent Pre-Test and Post-Test Control-Group Design. The test instruments based on aspects of understanding ability according to Anderson and scientific consistency tests were adapted from the form R-FCI. Subjects of this research were students of senior high school grade $X$ in senior high school consisting of two classes with total of 82 students. The research results showed Physics learning using multiple can more improve ability in understanding with mean score of normalized gain $(<\mathrm{g}\rangle$ ) by 0.79 (high criteria) than Physics learning without using multiple representation with mean score of $\langle$ g $>$ by 0.60 (medium criteria). Moreover, scientific consistency and representation showed students who get Physics learning using multiple representation increased in consistency quantity $(<c\rangle)$ by $\mathbf{7 4 . 8 \%}$ for scientific consistency and $72.3 \%$ for representational consistency (high criteria) higher than students who get Physics learning without using multiple representations with $\langle c\rangle$ by $\mathbf{5 5 . 3} \%$ for scientific consistency and $\mathbf{5 3 . 9 2 \%}$ for representational consistency. It can be concluded that Physics learning using multiple representation can more improve the ability of students in understanding of Physics material and scientific consistency significantly than Physics learning without using multiple representation.
\end{abstract}

Keywords- multiple representation, understanding, scientific consistency

\section{INTRODUCTION}

The role of multiple representations in learning is an important topic in the area of educational research. Multiple representations such as text, diagrams, graphs, and equations are often required to understand the Physics material. Multiple representation capability is the ability to represent all the same concept with different formats, including verbal, drawing, mathematics and graphs [1].

Multiple representation has three main functions, namely as a complement (to provide supplementary information or help completing the cognitive processes), limiting interpretation (to limit the possibility of interpretation error in using other representations) and the builder of understanding to encourage students to build understanding of the situation deeply [2]. In addition multiple representations help develop understanding of students of Physics problem, building bridges between verbal and mathematical representation, and help students develop an idea that gives meaning to the mathematical symbol [3].

Physics is a science that studies the relationship between the magnitudes in a natural phenomenon. Physics is a difficult subject because Physics requires students to hold the different representations simultaneously and manage changes between these representations [4]. The ability in understanding of Physics material is very concerned with how to use the various languages of science (multiple representations) which will enable students to learn Physics through development of mentally ability to think properly [5]. Students often use their understanding of the Physics material properly in answering the questions but having trouble when the representation in questions is changed. This means that students are only able to apply a concept in the context that using certain representation, but fail if the representation is changed [6]. Neiminan et.al tried to develop a study to look the consistency of students in answering questions of multiple representation by make multiple representation test instrument on force material that developed from Force Concept Inventory (FCI) 1995 version, named Representational Variant From Force Concept Inventory (R- FCI). The purpose of the using of R-FCI is to know the students' level of consistency in answering the question, which is divided into the representational consistency and scientific consistency [7].

Representational Consistency is the consistency of students in answering questions and seeing the representation equality concept according what is believed to be true, without being seen whether or not the answer scientifically. In other words, 
even if the student answers incorrectly, as long as he is able to see equality of representation form of his answer, so he is said to be consistent in terms of representation. The scientific consistency is the consistency of students in answering questions and seeing the representation equality concept as what he believed the truth, and see whether or not the answer scientifically.

Multiple representation consistency of students on force material correlated with students' ability in understanding positively the meaning is student consistency in represented Physics material in different ways is one of the factor that support students ability to understand Physics material. Based on above conditions, it is important and interesting to investigate an increase in the ability of students in understanding the Physics material and scientific consistency after applied multiple representation on learning [8].

\section{METHOD}

The research used is a quasi-experimental method with Nonequivalent Pre-Test and Post-Test Control-Group Design. The population is students of senior high school grade $\mathrm{X}$ in one of West Bandung regency's senior high school. The sample of this research was chosen by sample nonprobability (or convenience sample) where the respondents or individuals selected based on the ease and availability.

The experimental class and control class were determined randomly. Both of groups were carried out pre-test and posttest. Treatment was only given to the experimental class. The treatment in the experimental class was learning by using multiple representation with student worksheet that contains student activities make multiple representation (images, verbal, table, and diagram) of a phenomenon or experimental.

The instrument for ability in understanding is multiple choice tests that based on indicators of ability in understanding according to Anderson [9]. Instrument in the form of a written multiple choice test amounted to 14 items which include indicators on ability in of the Newton's Law. To see an increase in students' mastery of concepts used normalized gain score $(<\mathrm{g}\rangle)$ [10].

Scientific consistency is measured by standard tests Representational Variant of the Force Concept Inventory (RFCI) developed by Nieminen et al [7]. R-FCI tests in the form of isomorphic tests (same concept and context) in the form of multiple choices with three different representations (verbal, images, graphics and pictorial). R-FCI consists of 27 items which are divided into nine themes and derived from first Law of Newton, the Second Law of Newton, and the third Law of Newton. Consistency of representation based on the consistency of student answers reviewed from representation, not looking correct or wrong in physics. While the scientific consistency based on truth and consistency of student answers reviewed from physics and representation.

To determine the consistency level of each student within the overall of the test, so calculated the mean from scores that obtained for all themes. The mean score will be in the interval of 0 to 2 . Based on the mean score, student consistency is categorized into three levels of consistency, which is consistent
(K), moderately consistent (CK) and inconsistent (TK). Category of consistency level is shown in Table 2.

\section{RESULTS AND DISCUSSION}

\section{A. Improvement of Ability in Understanding}

Ability in understanding of the Newton's Laws was assessed using multiple choice tests by 14 tests already qualified in validity and reliability. These tests were conducted twice: before treatment (pretest) and after treatment (posttest). The mean score of pretest and posttest are provided in Table 1.

TABLE I. The ReCAPITUlation of MEAN SCORE PRETEST AND POSTTEST OF ABILITY IN UNDERSTANDING

\begin{tabular}{ccccccc}
\hline Group & Tests & $\mathbf{X}_{\text {ideal }}$ & $\mathbf{X}_{\min }$ & $\mathbf{X}_{\max }$ & $\bar{X}$ & $\langle\boldsymbol{g}\rangle$ \\
\hline \multirow{2}{*}{ Exsperimental } & Pretest & 100 & 0 & 42,8 & 20,7 & 0.8 \\
& Posttest & 100 & 64.3 & 100 & 83.4 & High \\
& \multicolumn{7}{c}{ Criteria } \\
Control & Pretest & 100 & 0 & 42.8 & 20.4 & 0.6 \\
& Posttest & 100 & 35.7 & 92.8 & 68.3 & Criteria \\
\hline
\end{tabular}

Table 1 showed improvement of ability in understanding the experimental group and control group viewed from mean score of normalized gain $\langle\mathrm{g}\rangle$. The experimental group has $\langle\mathrm{g}\rangle$ of 0.8 (high criteria), while the control group has $\langle\mathrm{g}\rangle$ of 0.8 (medium criteria). Since all data are normally distributed and homogeneous, so the hypothesis test is determined by parametric statistics test by using t-test as. Since $\mathrm{t}$ calculation (6.219) > ttabel 1.665, the hypothesis H0 is refused at significance level 0.05 . This means that problem based learning by using multiple representation improve the ability in understanding better than problem based learning without using multiple representation.

\section{B. Scientific Consistency of Students}

Scientific consistency data were obtained from the pretest and posttest results measured by using a standard test R-FCI with score in the range of 0 to 2 . Scientific consistency of the students is based on the truth and consistency of the student's answers scientifically and in term of representation. Figure 1 presents recapitulation of the percentage of the quantity of students at each level of scientific consistency. W note that initial test in the experimental group and the control group all students at level of TK (not consistent). After the posttest, both groups change in the quantity but different in amount. The experimental group changes in the quantity $4.8 \%$ at level of TK, $60.9 \%$ at the level of CK (consistent enough) and $34.1 \%$ at levet of $\mathrm{K}$ (consistent) whereas the control group is $43.9 \%$ at level of TK, $56.1 \%$ at the level of CK and no student at the level of K. At pretest, students are still not accustomed and familiar with multiple representations that were given. Pretest results also show that students' initial knowledge of the material Newton's Law is still low. 


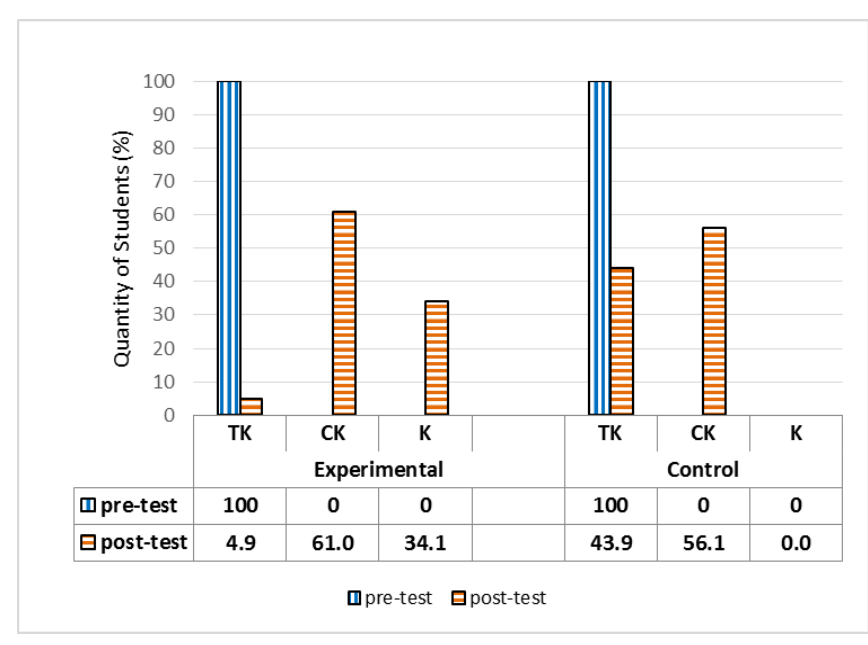

Fig. 1. Diagram quantity of students at each level of scientific consistency

\section{Representational Consistency of Students}

Students' representational consistency data were obtained from the initial test and final test measured by using traditional test instrument, the same test as to measure the scientific consistency. Representational consistency of students is based on consistency of students's representation but not corrects or not correct scientifically. Scores that obtained were in the interval 0 to 2 . Figure 2 provides recapitulation of the percentage of the number of student at each scientific consistency level.

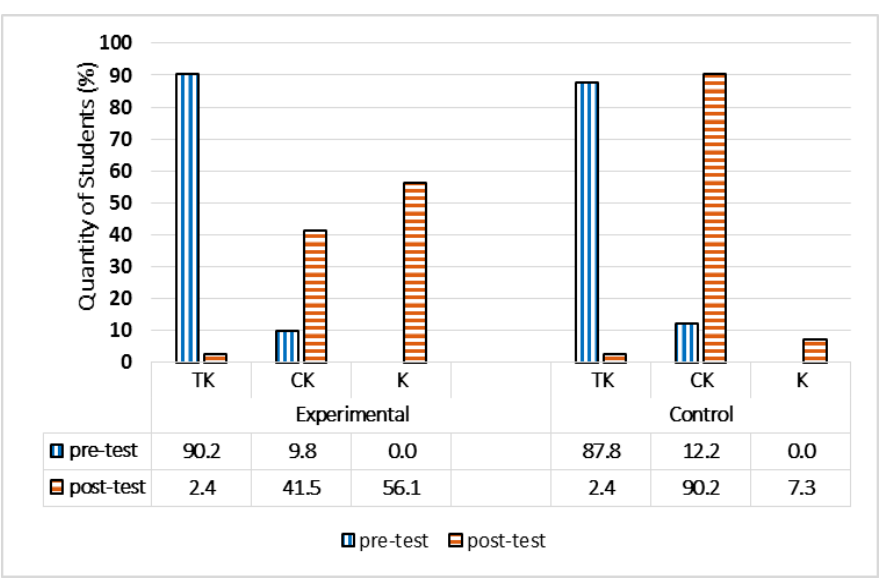

Fig. 2. Quantity of students at each level of representational consistency

From figure 2, it is known that the initial test in the experimental group and the control group at the level of TK with not much different, the experimental group $90.2 \%$ and $87.8 \%$ for the control group. After the posttest, both groups have same quantity at the TK level $(2.4 \%)$. In experimental group, a largest quantity at the level of $\mathrm{K}(56.1 \%)$ and in control group at the level of CK $(90.2 \%)$. For the control group, there is no student who answered consistent by representation.

In the ability in understanding tests, there are some questions with different representations and the answers require accuracy. The ability to construct and move from one representation to another representation require in answering the test that contain representation of the test. The experimental group during the learning gain multiple representation with exercise constructing multiple representation in the worksheets so that when finding a test that have multiple representation will not be difficult in answering test. Multiple representation useful in Physics education, because foster students' understanding of the physics tests, build bridges between verbal representation and mathematics, and help students develop an idea that gives meaning to the mathematics symbol [11]. The researchers stated that students should be taught to construct multiple representations and how to move between representations.

The representation ability of the students can be affected by the approach or the teachers teach concepts in class [12]. By entering multiple representations into the Process of Physics learning, students facilitated to know and train multiple representational ability. Students may be familiar with the type of representation of graphs, diagrams, pictures and verbal statements of Physics material are being studied, so it is expected that students can understand the concept as a whole with the types of representation.

Scientific consistency and representational consistency appears simultaneously. Both are related in determine the extent of achievement of the students' understanding. Recapitulation quantity percentage of student posttest results of two groups the scientific consistency and the representational consistency is presented in Figure 3 and 4.

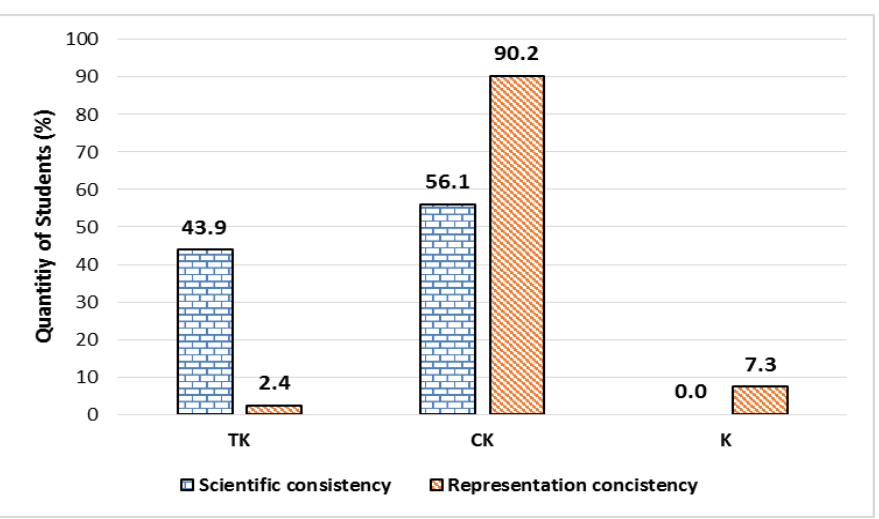

Fig. 3. Recapitulation Quantity Percentage of Students Posttest Results Experimental Group

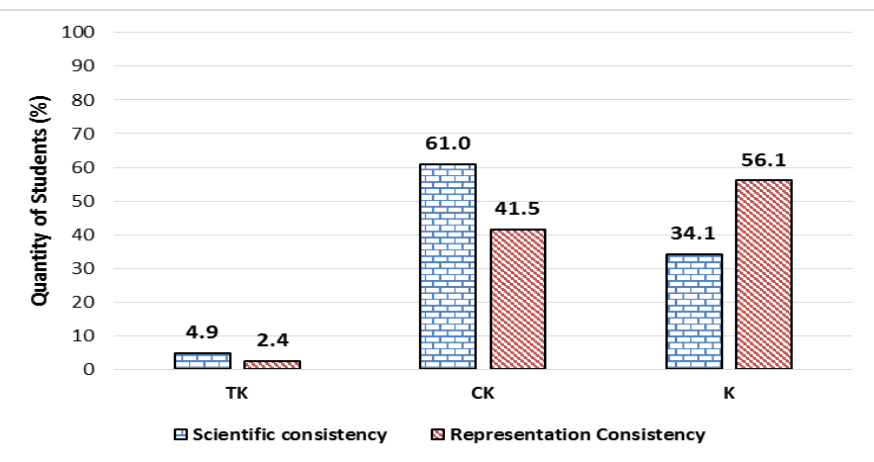

Fig. 4. Recapitulation Quantity Percentage of Students Posttest Results Control Group 


\section{CONCLUSION}

The research results showed Physics learning using multiple can more improve ability in understanding with mean score of normalized gain $(\langle\mathrm{g}\rangle)$ by 0.79 (high criteria) than Physics learning without using multiple representation with mean score of $\langle\mathrm{g}\rangle$ by 0.60 (medium criteria). Moreover, scientific consistency and representation showed students who get Physics learning using multiple representation increased in consistency quantity $(<\mathrm{c}>$ ) by $74.8 \%$ for scientific consistency and $72.3 \%$ for representational consistency (high criteria) higher than students who get Physics learning without using multiple representations with $\langle c\rangle$ by $55.3 \%$ for scientific consistency and $53.92 \%$ for representational consistency. It can be concluded that Physics learning using multiple representation can more improve the ability of students in understanding of Physics material and scientific consistency significantly than Physics learning without using multiple representation.

\section{REFERENCES}

[1] Waldrip, B., Prain, V., Sellings, P. (2013). Explaining Newton's Laws of motion: using student reasoning through representations to develop conceptual understanding. Instr Sci 41, pp. 165-189.

[2] Ainsworth, S. (1999). The function of multiple representations. Computer \& Education, 33. pp. 131-152.

[3] Ulvarina, (2010). Penggunaan Multirepresentasi pada Pembelajaran Konsep Gerak untuk Meningkatkan Kemampuan memahami dan
Memperkecil Kuantitas Miskonsepsi Siswa SMP. Tesis Program Pasca Sarjana UPI. Bandung.

[4] Nulhaq. S. (2013). Analysis of Students's Multiple Representation Capabilities Profile Based The Results of Limited Descriptions Test and Structured Descriptions Test at Junior High School. Skripsi Pendidikan Fisika UPI. Bandung.

[5] Abdurahman, dkk. (2011). Implementasi Pembelajaran Berbasis Multi Representasi untuk Peningkatan Penguasaan Konsep Fisika Kuantum. Jurnal Cakrawala Pendidikan, Februari 2011, Th. XXX, No.1.

[6] Savinainen, A. dan Virri, J. (2004). A case study evaluating students' representational coherence of newton's and second law. Prosedings Conference Proceedings No.720, editing by J. Marx, S. Franklin, and K.Cumings (AIP, New York, 2004), pp. 77.

[7] Nieminen, P., Savinainen, A., dan Virii, J. (2010). Force Concept Inventory-based multiple-choice test for investigating students' representational consistency. Phys. Rev. ST. Phys. Educ. Res. 6(2). 020109(12).

[8] Nieminen, P., Savinainen, A., dan Virii, J. (2012). Relation between representational consistency, conceptual understanding of the force concept, dan scientific reasoning. Phys. Rev. ST. Phys. Educ. Res. 8(1). 010123(10).

[9] Anderson, L.W. dan Krathwohl, D.R. (2001). A taxonomy for learning, teaching, and assessing. New York: Longman.

[10] Hake, R. (1999). Analyzing Change / Gain Scores. American Educational Research Association. From http://www.Physics.indiana.edu/ sdi/ Analyzing Change-Gain.pdf.

[11] Van Heuvelen, A. dan Zou, X. (2001). Multiple representations of workenergy processes. Am. J. Phys. 69(2). pp. 184-194.

[12] Kohl, P.B., et. al. (2007). Strongly and weakly directed approaches to teaching multiple representation use in Physics. Jurnal Physical Review Special Topics - Physics Education Research 3, 010108 _2007. US: The American Physical Society. 